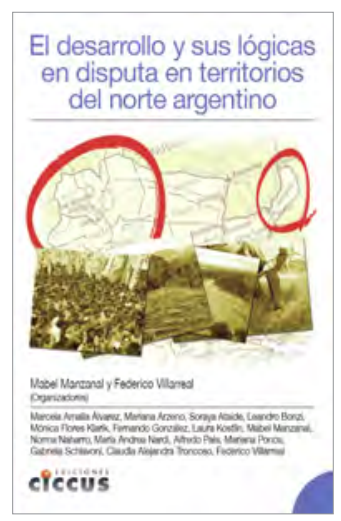

Mabel Manzanal y Federico Villarreal entregan en este libro una presentación exhaustiva de los diversos discursos, abordajes, experiencias y dinámicas de cambio que se combinan a la hora de pensar y actuar en territorios rurales. El estudio refiere al Norte argentino, pero la cuestión central que permea su contenido tiene un carácter que trasciende dicha geografía, remitiendo al debate sobre el desarrollo local-rural en el escenario de globalización en curso.

La decisión de colocar la perspectiva endógena o "localista" en el centro de sus reflexiones críticas no necesita mayor fundamento; esta usina teórica inspira las recomendaciones de política para paliar la pobreza, apoyar la pequeña agricultura familiar y, más ampliamente, promover el desarrollo rural que emanan de los organismos multilaterales de financiamiento internacional (BID, BM). Sintéticamente, bajo el estilo focalizado de la política social rural se combina la perspectiva del desarrollo territorial, articulando otra focalización: la comunidad local. Se presenta, entonces, como un tipo de desarrollo que se genera desde "abajo" hacia "arriba", sin grandes inversiones (obras públicas, infraes-

\section{El desarRollo y SUS lógicas EN DISPUTA EN TERRITORIOS DEL NORTE ARGENTINO}

\section{Mabel Manzanal y Federico Villarreal (Editores)}

Ediciones Ciccus | Buenos Aires

(FEBRERO DE 2010)

tructuras, etc.), induciendo el agrupamiento de voluntades colectivas a través de realizaciones en pequeños proyectos de productores y/o localidades pobres del medio rural. Desde hace más de una década, estos lineamientos se vienen aplicando en gran parte del continente latinoamericano.

El punto de partida es, entonces, la discusión del "paradigma dominante" -el Desarrollo Territorial Rural (DTR) o Desarrollo Local- profundizando la línea de estudio y reflexión presentada en un libro anterior organizado por Mabel Manzanal, Mariana Arzeno y Beatriz Nussbaumer (2007). Esta mirada crítica se refleja en el título del libro: El desarrollo y sus lógicas en disputa, y es la que configura la estructura del texto, a partir de la representación de las situaciones de conflicto y sus significaciones. Así, las condiciones de la ruralidad actual son las que se ponen en tensión para lograr un abordaje multidimensional de problemáticas y luchas en territorios rurales de la región más pobre de Argentina.

El libro se organiza en dos partes. La primera corresponde al planteo del enfoque analítico 
implementado en las realidades estudiadas. Se presenta el debate en torno a la cuestión del desarrollo o, más específicamente, sobre las relaciones de poder que se imbrican dentro de un "modo de dominación institucionalizado" que, en cada momento histórico, asegura su legitimidad y perdurabilidad, si bien existe "la posibilidad de conflictos entre los actores respectivos" (pp. 21-22). En la segunda parte de la obra, donde se presentan los estudios de caso, se deduce el objetivo de reflexionar sobre la naturaleza de los conflictos, profundizando en la dimensión política del lugar, su necesario vínculo con las relaciones de poder existentes localmente y, en este contexto, el rol de los actores y las instituciones involucradas.

Adentrándonos en el texto, es en el primer capítulo-Desarrollo, poder y dominación. Una reflexión en torno a la problemática del desarrollo rural en Argentina- donde Mabel Manzanal emprende la tarea de contrastar el discurso del DTR, o "endógeno" retomando la perspectiva histórica del debate sobre el desarrollo en América Latina. Desde este andamiaje teórico va articulando y sistematizando trabajos recientes de importantes autores, como Bourdieu, Quijano, Santos, Sen, Harvey, entre otros. Logrando un texto casi pedagógico sobre los diferentes enfoques y su influencia en el discurso y accionar del desarrollo.

La propuesta metodológica de analizar el lugar -el territorio- partiendo de las situaciones de conflicto y, por lo tanto, su vínculo con las relaciones de poder y la lucha desigual por sus recursos y representaciones, se imbrica con la necesidad de asumir el desafío de emprender la "descolonización epistemológica" planteada por Quijano (2000), que la autora explicita. Por un lado, desgranando "las propuestas del desarrollo rural, desarrollo local y DTR elaboradas a partir de visiones prácticas de desarrollo endógeno provenientes de los países centrales" (p. 29). Por otro, profundizando en los objetivos y resultados obtenidos por los programas inspirados en esta vertiente, particularmente, a través de uno de los discursos más seductores "el empoderamiento-participación de los actores locales".

$\mathrm{Al}$ respecto, Mabel Manzanal señala que "estas propuestas constituyen un modelo pseudoparticipativo (...) y son, en esencia, funcionales al orden social hegemónico" (p. 35). La autora sustenta esta afirmación analizando con minuciosidad evidencias que surgen de la implementación de programas de desarrollo rural en Argentina, concluyendo que este tipo de acciones "terminan favoreciendo el funcionamiento de mecanismos clientelísticos, no sólo desde el Estado sino, también, desde las ONGs e, incluso, desde los mismos técnicos" (p. 40). Más adelante, en el estudio de caso de la Quebrada de Humahuaca (Arzeno y Troncoso, p. 236), surgen otras evidencias sobre los procesos "participativos" y la falta de respuestas a las demandas concretas realizadas por la población local, en general, esenciales para la reproducción familiar (tierra, vivienda, salud).

En suma, la mirada expuesta por Manzanal en un período de profunda confusión conceptual, con usos abusivos de categorías analíticas generadas para explicar realidades diferentes, es motivadora y estimulante. Manifestar, fundamentada y explícitamente, esta necesidad de "descolonizar" y de recuperar el debate esencial en torno a las relaciones de poder y dominación, no es un desafío teórico menor. Supone, entre otras cosas, optar por un rumbo analítico desmitificador, rebatiendo la hiperflexibilidad y fluidez conceptual (Vainer, 2000) que opera, muchas veces, como un poderoso instrumento ideológico, oscureciendo (u ocultando) las lógicas globales que en su esencia van imprimiendo las lógicas territoriales. En este sentido, uno de los aportes significativos de esta obra es su visión analítica y empírica sobre la lucha por el lugar (concepto que tiene ciertas ligazones con el de la lucha de clases) "donde el propio orden institucional provee los mecanismos para enmascarar estas relaciones de poder y dominación “( p. 21). 
Otro aporte de esta obra es, sin duda, el reunir en un mismo texto estudios pormenorizados de los conflictos que, por su carácter, trascienden a los lugares donde se recogieron las evidencias. Esta parte del texto tiene la virtud de ser completa y exhaustiva en los objetivos que los autores se propusieron en su "estudio de caso" y, lo que no es menos importante, le confiere a todo el contenido un sentido de unidad y articulación orgánica en torno a los interrogantes y línea exploratoria sobre las "lógicas en disputa" en los territorios rurales bajo análisis.

Los trabajos referidos a las provincias de Misiones, Salta y Jujuy exhiben con rigurosidad teórico-metodológica la diversidad de problemáticas, profundizando en las disputas por la propiedad y/o uso de la tierra; por el agua, el medio ambiente, las estrategias de reproducción y supervivencia de la pequeña agricultura familiar, las transformaciones recientes de las áreas agrorrurales. En definitiva, una visión que, a través de los conflictos, permite desgranar procesos y dinámicas fundamentales del capitalismo que, en su actual lógica globalizante, profundiza la valorización-explotación de los recursos naturales aunque, como señalara Castell (1987), ello signifique la exclusión del circuito de acumulación y de redistribución a amplios sectores sociales y regiones del planeta.

Los análisis sobre la disputa por la tierra, en la provincia de Misiones y el Chaco Salteño, contextualizan las raíces históricas y estructurales del conflicto, a partir de las cuales cobra forma y cuerpo la disputa actual. Las tierras del nordeste misionero están tensionadas por la revalorización más reciente del complejo foresto-industrial que profundiza la concentración y extranjerización de la propiedad de los bosques, provocando un conflicto entre los "ocupantes" y los "propietarios", intermediado por una dimensión público-política. Ambos trabajos (Kostlin; Arzeno y Ponce) reflejan esta experiencia de lucha por la tierra profundizando en su significado y en las propias contradiccio- nes: entre productores familiares ocupantes y propietarios (grandes y medianos); entre el gobierno provincial -propietarios/ocupantes; entre los propios "ocupantes" y sus organizaciones.

El estudio de Naharro, Álvarez y Klarik sobre la lucha por la titulación de la propiedad de la tierra en el Chaco Salteño, confronta el contenido de un "catálogo de discursos socialmente legitimados" (p. 152) en el marco de dos dinámicas en tensión: el derecho otorgado a los pueblos originarios por la Constitución de 1994 y la expansión de la frontera agrícola expresada en el llamado fenómeno de la sojización. Desde esta visión se amalgama el hilo argumental del discurso "productivista" que, en palabras de las autoras, "se vincula más estrechamente con la organización política del Estado" (p. 151), en el discurso "campesino" asociado a los postulados de la reforma agraria difundido en el continente durante la década del 50-60 del siglo XX y, los más contemporáneos, que devienen del discurso ambientalista-ecologista, es decir, el "preservacionista" y sus variantes "multicultural" y de la "biodiversidad".

Siguiendo la clasificación de conflictos que implementan en el Programa de Investigación -entregado al final del libro- una segunda disputa aparece asociada al medio ambiente. En el marco de las transformaciones de la cartografía minera en Argentina, y el devenir de una actividad liderada por las corporaciones mineras globales, el trabajo de Leandro Bonzi desglosa las dos lógicas que se confrontan tras el negocio de la minería. Una, la del Estado nacional y provincial, y la vocación guiada, más allá de sus matices, por la apropiación de una parte de la renta generada por la actividad minera. La otra lógica es la de la población local y su diversidad a través de la lucha de los "autoconvocados", que en palabras del autor son "organizaciones territoriales", en la medida que se constituyen "como actores en tanto partícipes de una disputa por la forma que adoptará su territorio en términos materiales" (p. 213). 
Una lucha por el lugar que trasciende el conflicto por la mina de uranio de Don Otto, de propiedad de la Comisión Nacional de Energía Atómica (CNEA), y anticipa la expansión de la problemática ambiental en zonas aledañas por las 35 concesiones mineras otorgadas por el gobierno de la provincia de Salta. En definitiva, como señala el autor, intersticios entre el adentro y el afuera, entre lo público y lo privado, entre la naturaleza y el estancamiento, entre la "injusticia ambiental" y otras amplias "injusticias sociales" que llevan directamente a los problemas de inclusión y exclusión.

La otra disputa, exhaustivamente analizada por Villarreal, es la del agua de riego, recurso esencial para la agricultura del departamento de San Carlos en la provincia de Salta. La génesis del conflicto entre grandes y pequeños productores por la utilización del recurso es analizada desde la perspectiva de la governance, es decir, a través de los instrumentos, instituciones regulatorias y alianzas que históricamente han enmarcado las relaciones de poder en torno al recurso. En esa secuencia analítica, entonces, se reflejan los diferentes modelos públicos en la administración del agua desde la intervención directa a los difundidos "consorcios de regantes", que se impusieron en el contexto de las políticas liberales de los 90. Ante este escenario, el cambio institucional reciente supone la reanudación de un esquema que, al menos desde el discurso, plantea interceder en las desiguales relaciones de poder expresadas en las tomas de agua.

Otras problemáticas de los pequeños productores, a partir del caso de Cachi (País, 155-268), remiten a metamorfosis del medio rural derivadas de las infraestructuras de transporte, las TIC y, más en general, de la condición rural en su actual significación tras el advenimiento de lo urbano generalizado. Hay aquí un cruce analítico interesante cuyo recorrido revela la migración de los jóvenes por falta de trabajo, pero también por el acercamiento y difusión del ideal urbano.
Intervienen en este fenómeno también otras variables: el rol de la educación en este proceso de desagrarización; la pluriactividad generalizada entre las familias campesinas; las limitaciones de acceso a mercados y precio para los productos de la pequeña agricultura familiar, versus el rol de las comunicaciones (telefonía celular, internet) en el acceso a información de mercados más distantes; las lógicas empresariales y de acumulación que se han ido delineando con la intensificación de la actividad turística y el accionar de los nuevos actores empresariales; los límites que devienen del supuesto dinamismo económico impreso por el turismo rural. En esencia, la complejidad de procesos que hoy tensionan las condiciones de reproducción de la pequeña agricultura familiar y sus lugares de vida y trabajo.

Por último, tres estudios referidos a politicas e intervenciones de apoyo a la pequeña agricultura familiar y, más ampliamente, el desarrollo rural. Así, las ferias francas de Misiones, en tanto experiencia de construcción de mercado (Schiavoni, pp. 113-132), es examinada a través de las lógicas del proceso social involucrado en esta organización mercantil. Intervienen los pequeños agricultores, principalmente mujeres, y los técnicos de ciertos programas de desarrollo rural. La autora realiza una interesante reflexión en torno a otras lógicas en tensión, propias del ejercicio de mediación que surge de estos programas públicos, en la medida en que acompañan y/o impulsan "el proceso de mercantilización" de la pequeña producción familiar. En un capítulo anterior, por su parte, Nardi (pp. 91-112) coloca el accionar de estos programas en el marco de las transformaciones que experimenta el territorio agrorrural misionero desde la década de los 90, explicitando los "dos modelos de desarrollo rural” que estarían en disputa. Uno, inclusivo de la agricultura familiar y sus estrategias de reproducción (producciones con tecnología apropiada, orgánicas, etc.), el otro es el de la "agricultura industrial" (p. 101), orientado a la inserción en mercados 
globales. Las experiencias misioneras que resalta la autora se inscriben en una de las "arenas del desarrollo rural" que hace posible prácticas, movimientos, acciones, percepciones e imágenes que, en cierto modo, abonan el discurso de la resistencia.

El trabajo sobre la Quebrada de Humahuaca (Arzeno y Troncoso, pp. 223-246) exhibe y discute aspectos relativos a las contradicciones locales frente a la irrupción de las fuerzas exógenas ligadas a la actividad turística, estimulada a partir de la designación del lugar como "Patrimonio de la $\mathrm{Hu}$ manidad". La condición agroturística del territorio de la Quebrada de Humahuaca remite, entonces, a varios modelos y lógicas en disputa: "Entre un uso residencial y otro turístico" (p. 240); "entre empresarios foráneos y quebradeños"; por los efectos del accionar de la política pública centrada en el turismo, por los desplazamientos generados con la expansión del capital inmobiliario, y conflictos entre diferentes organizaciones locales-extra-locales. Más aún, hay procesos permeados por intereses del capital global (fundación Monsanto; financiamientos internacionales) que se traducen en la explotación económica de la "especificidad" del lugar -el atributo cultural o el saber- a través de diferentes proyectos (papa andina; aprovechamiento fitogenético).

En suma, la obra que nos presentan Manzanal y Villarreal ofrece un panorama completo de la discusión actual en torno a la pobreza rural y las realidades que atraviesan a la llamada nueva ruralidad. Este análisis se nutre de problemáticas y conflictos que abarcan desde la tenencia de la tierra, los pueblos originarios, el medio ambiente, el agua hasta la minería y el turismo. El balance global de sus aportes, en una apretada síntesis, remite a:

- Un debate lúcido que permite contrastar, con argumentos teóricos y empíricos, el andamiaje clave del "paradigma dominante" en materia de desarrollo rurallocal, esto es: la "voluntad colectiva", la "cooperación", "empoderamiento-participación". Para la perspectiva dominante estas son, precisamente, las condiciones de construcción social que le dan entidad al territorio y a las regiones rurales. En esencia, cerramientos sin conflictos y contradicciones con capacidad para desarrollar estrategias autorreproductivas y moldear la endogeneización de dinámicas de desarrollo.

- Todo ello conduce a explicitar que la ruralidad de los nuevos tiempos se construye económica, social y políticamente en torno a la lucha por los recursos productivos, la mercantilización del medio ambiente y, entre otros, cuestiones relacionadas con el control de los sistemas locales de alimentación. Se trata de una contienda dura y compleja donde intervienen las grandes corporaciones globales, las instituciones internacionales, el Estado y los diferentes grupos sociales que convergen en el medio rural.

- Elementos de información y análisis sobre el accionar de gobiernos provinciales y locales, como una de las facetas del complejo proceso de redefinición-posicionamiento que atraviesa el Estado en la actual etapa de exacerbación de la explotación de la naturaleza. Frente a los nuevos y viejos negocios generados con la explotación de los recursos naturales -minerías, turismo, soja, madera, entre otros-, el discurso del desarrollo rural, y su implementación política parece operar como una especie de "cortina de humo" o, a lo sumo, una muy corta frazada para los desplazados de siempre.

- Un análisis exhaustivo de las principales problemáticas que atraviesan a las poblaciones rurales pobres, la agricultura familiar y poblaciones originarias, desde una perspectiva que amplifica interrogantes en torno a las tendencias de cambio en otras realidades rurales. Hay aquí temáticas referidas a las nuevas re- 
percusiones de las tecnologías de información y comunicación, nuevos usos y actividades con sus efectos socioambientales, y múltiples y variadas estrategias de sobrevivencia y luchas de nuevo tipo.

\section{Referencias bibliográficas}

Castells, M. (1987). El nuevo modelo mundial de desarrollo capitalista y el proyecto socialista. En A. Guerra et al. Nuevos horizontes teóricos para el socialismo. Madrid: Sistema.

Manzanal, M., Arzeno, M. \& Nussbaumer, B. (Eds.) (2007). Territorio, poder e instituciones. Una perspectiva critica sobre la producción del territorio. Buenos Aires: CICCUS.

Vainer, C. (2000). Pátria, empresa e mercadoria. Notas sobre a estratégia discursiva do Planejamento Estratégico Urbano. Em Aranes O., Vainer C. \& Maricato, E. A cidade do pensamento único. Desmanchando consensos (pp. 75-103). Petrópolis: Editora Vozes.

\section{Silvia Gorenstein}

Investigadora del Consejo NaCional de INVESTIGACIONES CientíficAS Y TÉCNICAS (CONiCET) - Profesora Titular en el Departamento de Economía de la Universidad Nacional del Sur, Bahía Blanca, Argentina;

E-MAIL:SGOREN@CRIBA.EDU.AR 